\title{
Evidence of widespread illegal hunting of waterfowl in England despite partial regulation of the use of lead shotgun ammunition
}

\author{
David A. Stroud ${ }^{1}$, Deborah J. Pain ${ }^{2}$ \& Rhys E. Green ${ }^{2 *}$ \\ ${ }^{1}$ Spring Meadows, Taylors Green, Warmington, Peterborough PE8 6TG, UK \\ ${ }^{2}$ Department of Zoology, University of Cambridge, Downing Street, Cambridge CB2 3EJ, UK
}

https://doi.org/10.52201/CEJ18GRKF2551

\begin{abstract}
SUMMARY
Shooting of birds using lead shotgun ammunition was legal for all quarry species in the UK until $1^{\text {st }}$ September 1999, when the Environmental Protection (Restriction on Use of Lead Shot) (England) Regulations 1999 and similar regulations in other UK countries came into effect. These regulations made it illegal to shoot ducks and geese and some other waterfowl species in England with lead shotgun ammunition and/or to use it in certain wetland habitats. The legislation was intended to reduce the incidence of lead poisoning of wetland birds caused by ingested and embedded shotgun pellets. We evaluate the effectiveness of this legislation by estimating the number of ducks shot in England with lead shot. We also assess the effectiveness of awareness-raising actions about the regulations, including an advocacy campaign intended to encourage compliance, and an undertaking by the UK Government to examine ways to improve compliance and enforcement. We estimate that about 13 million ducks have been shot illegally using lead shotgun ammunition in England since $1^{\text {st }}$ September 1999 - an annual average of approximately 586,000 and representing approximately $70 \%$ of the total ducks shot. There was no detectable decline in the number of ducks killed using lead shotgun ammunition following the awareness-raising publicity and advocacy campaign by shooting and countryside management organisations. The government review of implementation and enforcement of the Regulations on the level of this wildlife crime was not followed by any new prosecutions. There has been one prosecution for an offence under the Lead Shot Regulations. We conclude that the 1999 Regulations and attempts to promote compliance with them have effected only a small reduction in the use of lead shotgun ammunition in wetlands in England.
\end{abstract}

\section{BACKGROUND}

Illegal killing or taking of birds is widespread internationally. Between 11 million and 36 million birds of all species are estimated to be killed illegally each year in the Mediterranean region, comprising southern Europe, North Africa and the Middle East (Brochet et al. 2016) and the annual illegal take of birds has been estimated to be 0.4 to 2.1 million in the adjacent region comprising northern and central Europe and the Caucasus, which includes the UK (Brochet et al. 2019). The legal prohibition or regulation of the taking of animals and the methods used to take them is a fundamental conservation tool. However, legislation does not, by itself, always effect large changes in human behaviour. For example, birds of prey continue to be killed illegally in considerable numbers in the UK, despite protection given by the Wild Bird Protection Act (1880) and the Protection of Birds Act (1954, 1964, 1967) and other legislation (Stroud 2003, RSPB 2020a).

The UK government has long accepted that there is a significant problem of lead poisoning of waterbirds in UK wetlands caused by ingested and embedded lead shotgun pellets used for hunting. Consequently, the UK has a long-standing obligation to phase out the use of lead shot over wetlands as a Contracting Party to the AfricanEurasian Migratory Waterbirds Agreement (AEWA 1999, 2002, 2008). To address this problem in English wetlands, the Environmental Protection
(Restriction on Use of Lead Shot) (England) Regulations 1999 came into effect from 1st September 1999. Since that time, it has been illegal to use lead shotgun ammunition for killing all Anatidae (ducks, geese and swans), Eurasian coot Fulica atra and common moorhen Gallinula chloropus and/or for shooting over any area of foreshore (defined as below high-water mark of ordinary spring tides) or on or over any Site of Special Scientific Interest in England included in Schedule 1 to the Regulations (Her Majesty's Stationary Office 1999, 2002, 2003). Similar restrictions apply in Wales and others apply in Scotland and Northern Ireland. Hence, the use of lead shot to kill waterfowl and/or over wetlands has been illegal throughout the UK since 1999. There are no formal estimates of the proportion of waterfowl killed using lead ammunition before 1999 , but it is widely accepted that this proportion was almost $100 \%$, as remains the case for the most widely-hunted non-wetland birds (Green et al. 2021).

We assess the effectiveness of the lead shot regulations by estimating the numbers of ducks that have been killed illegally in England using lead shotgun ammunition over a period of more than 20 years after the legislation came into effect. We also describe efforts to encourage compliance with the legislation, including law enforcement, and the extent to which they have been effective. 


\section{ACTIONS}

The Environmental Protection (Restriction on Use of Lead Shot) (England) Regulations 1999

Referred to as the Lead Shot Regulations, this Statutory Instrument came into effect in England on $1^{\text {st }}$ September 1999 following an unsuccessful voluntary process over a 4-year period to phase out the use of lead shotgun ammunition in wetlands (Stroud 2015). It was amended in some details in 2002 and 2003.

Awareness raising about the Lead Shot Regulations and the 'Use Lead Legally' campaign

Since the Lead Shot Regulations came into force, some shooting and countryside management organisations have consistently encouraged duck hunters to comply with the law and have provided accurate information on the availability and efficacy of non-lead shotgun ammunition (e.g. BASC 2009). However, results of monitoring the level of compliance with the Regulations by forensic examination of shot wild ducks purchased in England, and likely to have been shot there (Cromie et al., 2002, 2010), indicated that the majority of ducks sampled from 1999 to 2009 had been killed illegally using lead shotgun ammunition. In addition, Newth et al. (2012) found elevated blood lead levels in a third of live-captured wildfowl tested in Britain in 2010 and 2011 and no reduction in the proportion of recorded wildfowl deaths attributable to lead poisoning in an 11-year period (1999-2010) following the introduction of the legislation in England. These indications of a continuing problem gained considerable media coverage, including in magazines read by duck hunters, such as Shooting Times and Shooting and Conservation.

The UK Government's Department of Environment, Food and Rural Affairs (Defra) and the Food Standards Agency (FSA) convened the Lead Ammunition Group in 2010 to evaluate concerns about risks to wild and domestic animal health and human health from all uses of lead ammunition. It was therefore appreciated by UK shooting and country land management organisations that non-compliance with the current law related to the use of lead shot might, in future, put at risk the continued legality of use of all lead ammunition for all quarry species and in all habitats (Cromie et al. 2015). Several organisations came together in the summer of 2013 to launch a campaign to encourage individuals to comply with the law on the use of lead shot. This 'Use Lead Legally' campaign was given a high-profile launch at the Country, Land and Business Association (CLA) Game Fair in July 2013 and was widely reported in the shooting media and in the magazines of shooting organisations at the time (BASC 2013a) and for some years afterwards (Graffius 2014, Ellis 2017). Members of these organisations were invited by the campaign to sign a pledge that they would not break the law in this regard (BASC 2013b).
Defra assessment of potential improvements to the implementation and enforcement of the Lead Shot Regulations

In 2015, the Lead Ammunition Group included information on large-scale lack of compliance with the Lead Shot Regulations in its report to the Defra Secretary of State on all aspects of the use of lead ammunition in the UK. When the then Secretary of State for the Environment, Food and Rural Affairs, Elizabeth Truss, responded to the Lead Ammunition Group report on $12^{\text {th }}$ July 2016, she stated "I do, however, recognise that there appears to be an issue with poor compliance with the Lead Shot Regulations and I can confirm that Defra will look at how the existing Regulations on wildfowling can be better implemented" (Truss 2016). On $7^{\text {th }}$ November 2016, the then Defra Parliamentary Under Secretary of State Dr Thérèse Coffey wrote to the Chair of the Lead Ammunition Group to confirm that "Officials are currently looking at options on how to enforce the regulations more effectively, such as in Sites of Special Scientific Interest" (Coffey 2016).

\section{METHODS}

Estimating the numbers of ducks shot in the UK 1999-2020

Duck shooting in the UK is typically organized by wildfowling clubs in coastal areas and inland, and also on some shooting estates where captive-bred mallard Anas platyrhynchos are released. Almost uniquely in Europe, the UK has no formal bag reporting system nor any other formal means of assessing numbers of quarry species taken. However, Aebischer (2019) calculated UK annual bag totals for all nine frequently-shot species of ducks: northern shoveler Spatula clypeata, Eurasian wigeon Mareca penelope, gadwall Mareca strepera, mallard, northern pintail Anas acuta, Eurasian teal Anas crecca, tufted duck Aythya fuligula, common pochard Aythya ferina and common goldeneye Bucephala clangula. He used information from the Game and Wildlife Conservation Trust's National Gamebag Census (NGC), which gives an index of numbers shot in the UK for each species, and calibrated these indices against two independent surveys that gave information on the total number of all duck species shot in 2004 and 2012 (PACEC 2006, 2014). We used Aebischer's (2019) calculations, which allow conversion of annual indices of numbers of ducks shot to estimates of absolute numbers of birds killed in the UK in each of the years 2004, 2012 and 2016.

Proportion of the UK duck bag that was shot in England

We wished to obtain annual estimates for England of the numbers shot of all duck species rather than the UK as a whole, because monitoring of compliance with the Lead Regulations has only been conducted for England. The method used by Aebischer (2019) cannot be applied to give separate bag totals for the four UK countries because the 
absolute duck bag totals needed for calibration are only available for the UK as a whole (PACEC 2006, 2014). We therefore estimated the proportion of the UK bag of all duck species that were shot in England by using six country-specific measures of hunting opportunity taken from the PACEC reports (PACEC 2006, 2014); each method being based on either the proportion of providers of shooting opportunities (Table 1, Methods 1-3) or the proportion of gundays (Table 1, Methods 4-6).

The proportions of providers of different types of shooting in each of the four UK countries, were available for 2004 and 2012 (PACEC 2006, 2014). Initially, we used the coastal and inland wildfowling categories as these are most relevant to duck shooting. We multiplied the proportions of providers offering these two kinds of shooting by the total numbers of providers in each country (PACEC 2006, page 27; PACEC 2014, Table 33) to give the estimated number of providers of each type of shooting in each UK country (Method 1, Table 1). We took the proportion of the UK sum of providers of coastal and inland wildfowling located in England as a measure of the proportion of the UK duck bag shot in England, calculated separately for 2004 and 2012.

Unpublished analysis of NGC data for 2019 showed that $21 \%$ of those UK estates which release principally common pheasants Phasianus colchicus and/or red-legged partridges Alectoris rufa for shooting, also release captive-bred mallards (N.J. Aebischer in litt.). For 2004, we estimated the number of providers of 'driven lowland game' shooting for each UK country using the method described above. We multiplied these countryspecific totals of providers of driven lowland game by country-specific proportions of those shooting providers who shoot some pheasants or partridges who release some of these species, rather than relying entirely on wild-bred birds. The latter proportions were taken from PACEC 2006, page 9. We then multiplied the result of these steps by 0.21 from N.J. Aebischer (in litt.) to estimate the number of driven lowland game providers likely to release mallards for shooting. Finally, we added this estimate of the number of driven lowland game providers that released mallards to the numbers of providers of coastal and inland wildfowling and then calculated the proportion of combined duck shooting opportunity located in England, as described above (see Table 1, Method 2).

Data on the proportion of shoots releasing pheasant and partridge were not available for 2012, and analyses of NGC data showed that numbers of pheasants, red-legged partridges and mallards released for shooting had all increased during this period (Aebischer 2019). We therefore made two estimates for 2012 (Table 1): one based on the calculations described above using the data for 2012, but with data from 2004 on proportions of lowland driven shoots releasing birds (Table 1, Method 2). The second, an alternative estimate, assumed that all lowland driven shoots released birds in 2012 and that $21 \%$ of them released mallards, as estimated by Aebischer (2019) (Table 1, Method 3).

For all of the calculations we assumed that the average number of ducks shot per provider was the same in all four UK countries. However, shooting effort and success per provider may differ among countries. The PACEC reports do not provide country-specific values for shooting effort per provider for each type of shooting, but the number of gun-days for all types of shooting combined is given for each country (PACEC 2006, page 27; PACEC 2014, Table 33). We used this number of each UK country, in place of the number of providers per country, to give an alternative set of estimates (Table 1, Methods 4, 5 and 6, which are equivalent to Methods 1, 2 and 3 respectively) of the proportion of UK duck shooting located in England.

Table 1. Proportion of UK duck shooting opportunity calculated to be located in England by six methods, which make various assumptions as described in the text. The types of shooting included or excluded from the calculation of proportions of providers offering duck shooting are indicated in the second and third columns. Whether the shooting effort per provider was assumed constant (providers) or proportional to the number of gun-days offered in the country is indicated by the effort column. Proportions of opportunity in 2004 and 2012 are shown in the two right-hand columns, based on data presented in PACEC $(2006,2014)$.

Types of shooting included
Proportion of UK opportunity located in England

\begin{tabular}{cccccc}
\cline { 2 - 5 } Method & $\begin{array}{c}\text { Inland \& coastal } \\
\text { wildfowling }\end{array}$ & $\begin{array}{c}\text { Shooting of released ducks on } \\
\text { lowland driven shoots }\end{array}$ & $\begin{array}{c}\text { Measure of } \\
\text { effort }\end{array}$ & $\begin{array}{c}\text { Based on } \\
2004 \\
\text { data }\end{array}$ & $\begin{array}{c}\text { Based } \\
\text { on 2012 } \\
\text { data }\end{array}$ \\
\hline 1 & Yes & No & Providers & 0.672 & 0.789 \\
2 & Yes & Yes (2004 release proportions) & Providers & 0.705 & 0.809 \\
3 & Yes & Yes (all shoots release) & Providers & NA & 0.806 \\
4 & Yes & No & Gun-days & 0.720 & 0.836 \\
5 & Yes & Yes (2004 release proportions) & Gun-days & 0.749 & 0.852 \\
6 & Yes & Yes (all shoots release) & Gun-days & NA & 0.851 \\
\hline
\end{tabular}




\section{Prosecutions}

We requested the Investigations Department of the Royal Society for the Protection of Birds to provide us with all records for 1999-2020 of wildlife crimes involving birds in the UK for which prosecutions were brought under the Lead Shot Regulations and the number of those in which a conviction was obtained from their Species Protection Database.

\section{CONSEQUENCES}

Number of ducks shot in the UK 1999 - 2020

Aebischer (2019, Table 2) gives estimated numbers shot in the UK of the nine species of ducks for 2004, 2012 and 2016. The annual totals across all species in each of these three years were 966,080, $1,001,880$ and 1,136,200 ducks shot respectively. Most of these $(84 \%)$ were mallards. Aebischer (2019) provided $95 \%$ confidence intervals for the species-specific estimates for each of the three years, which indicated that the estimates for the most frequently shot species, and hence the total across all species, were reasonably precise. Although the three annual grand totals increase over time, the confidence intervals for the estimates of change in the UK bag of individual species over the period covered by the PACEC data, as shown in Aebischer (2019, Table 1), do not indicate any statistically significant increases. We therefore assumed that the UK bag remained constant throughout the period $1999-2020$ at the mean of the values for 2004, 2012 and 2016 derived from Aebischer (2019) $(1,034,720$ ducks per year).

Proportion of the UK duck bag shot in England For each method, estimated proportions of duck shooting in England were higher for 2012 than 2004, and when gun-days were used as the measure of shooting effort, rather than the number of providers (Table 1). The assumptions made about the proportion of lowland driven shoots that released birds made little difference to the proportions calculated for 2012. Given that we have no strong reasons to accept any one of these methods or sets of assumptions over the others, we calculated a weighted mean of the mean of all values for each year with the number of PACEC survey respondents in $2004(\mathrm{n}=1094)$ and $2012(\mathrm{n}=3843)$ as the weights. This gave a weighted mean proportion of duck shooting located in England of 0.799, with an overall range of values of $0.672-0.852$ (Table 1 ).

\section{Proportion of ducks shot in breach of the 1999} Regulations in England

Surveys of the proportions of shot ducks purchased in England in 2001, 2008, 2009 and 2013 that were killed illegally using lead shotgun ammunition have published (Cromie et al. 2015). Sampled ducks were believed to have been shot in England, as determined at time of purchase. Embedded shot were extracted and their metal type determined by forensic examination (see Cromie et al. (2015) and references therein). The proportions of ducks killed illegally using lead shotgun pellets in breach of the Lead Shot Regulations was high and showed some indication of an increase over time (68\%, 70\%, 70\%, 77\% respectively). However, variation among years in the proportion of illegallyshot ducks was not statistically significant $\left(\chi^{2}(3)=\right.$ $2.49, \mathrm{p}=0.476)$. A logistic regression model fitted to the data, with illegally-shot or not as the binary response variable and year as a continuous independent covariate, indicated a non-significant tendency for the proportion to increase over time (likelihood-ratio test; $\chi^{2}(1)=1.70, \mathrm{p}=0.428$ ). The fitted regression model of the proportion of illegallyshot ducks Q in relation to year was $\operatorname{logit}(\mathrm{Q})=$ $0.5199+0.0421$ YEAR (standard error of the slope $=0.0322$ ). We therefore assumed that the proportion of sampled ducks killed illegally did not change over time and used pooled results from all four surveys (518 shot using lead from 731 sampled) to indicate the level of non-compliance with the regulations. This proportion was 0.709 (Clopper-Pearson exact $95 \%$ confidence interval $0.674-0.741)$ (Clopper \& Pearson 1934).

Numbers of ducks shot in England in breach of the 1999 Regulations

We multiplied the estimated number of ducks shot in the UK by the weighted mean proportion of duck shooting located in England (from results in Table 1) and by the estimated proportion of ducks that are shot illegally in England. This calculation gives an estimated total number of ducks killed illegally in England between 1999 and 2020, in breach of the Lead Shot Regulations, of 12.9 million, with an annual mean of 586,000.

\section{Prosecutions for breaches of the Lead Shot Regulations}

One prosecution was recorded in the RSPB database during 1999-2020 for an offence committed in North Yorkshire in 2011 in which a person was fined for two charges relating to the shooting of a mute swan Cygnus olor. In addition to being fined for causing criminal damage to a swan, the person was fined $£ 100$ for the use of lead shot, in breach of the Environmental Protection (Restriction on Use of Lead Shot) (England) Regulations 1999 (RSPB 2011). No further prosecutions were brought after the government review of implementation and enforcement in 2016.

\section{DISCUSSION}

In the 22 years since the introduction of the Lead Shot Regulations approximately 13 million ducks have been killed using lead in England, giving an average annual number of approximately 600,000 birds, which is about $70 \%$ of the total duck bag. To the best of our knowledge, our estimate of the number of ducks killed in England using lead shotgun ammunition is the first defensible formal estimate of the scale of this illegal killing to be published. Previously, Brochet et al. (2019) concluded that "hundreds of thousands of ducks could potentially be classed as illegally killed [in the UK]", but they did not provide details of their 
calculation or make any allowance for the absence of bag data specific to England. Brochet et al. (2019) excluded illegal killing of ducks with lead shot in the UK from their compilation of data on European illegal bird killing, though they noted that "hunters are choosing to use lead gunshot for duck shooting rather than comply with the law". The reasons they gave for this exclusion were that there was "a lack of comparable information between countries/territories on the scale of this issue" and "complexities of how lead shot use is regulated at the state and province level". Had either their own rough estimate of this illegal killing or our new one been correctly incorporated in Brochet et al.'s (2019) compilation, the UK would have been ranked amongst the worst northern European countries in relation to compliance with bird conservation legislation. Based upon adding in our new estimate for England, the mean annual number of birds killed illegally in the UK is 72 times the value given by Brochet et al. (2019) and the illegal take per person in the UK ranks fifth highest among the 39 states they assessed, instead of 39th.

Compliance with partial statutory bans on the use of lead ammunition in wetlands may also be low in other European countries and, if data from these countries were available and included, this would also affect the UK's national ranking regarding levels of wildlife crime. Compliance with partial bans has seldom been measured in other European countries, but it is known to be high $(>95 \%)$ in Denmark where there has been a total ban on the use of lead shotgun ammunition for all hunting since 1996 (Kanstrup \& Balsby 2019). Limited information suggests that compliance with partial, habitat- or species-specific bans elsewhere in Europe may be lower than for the total ban in Denmark. In Sweden, there is a hunter-reported compliance level of about two-thirds with a statutory ban on the use of lead shotgun ammunition in wetlands and over the sea, which has been in place for about 20 years (Widemo 2021). In the Ebro Delta, Spain, a statutory ban on the use of lead shot for hunting in protected wetlands was fully implemented in the 2003 hunting season. Annual monitoring 2007-2008 and 2010-2011 found that compliance increased from under $60 \%$ to over $70 \%$ during this period - associated with increased enforcement and monitoring of hunter's ammunition (Mateo et al. 2014).

Since 1999, when the Lead Shot Regulations came into effect, there have been efforts to encourage increased compliance through awareness raising by shooting organisations and consideration of additional measures by the UK government. However, we found no indication that the annual number of ducks killed illegally in England decreased between 1999-2020. The estimated proportion of ducks killed illegally was similar immediately after the 2013 'Use Lead Legally' campaign by UK shooting and country land management organisations $(77 \%)$ to the level before the campaign (68-70\%) (Cromie et al. 2015). Preliminary results from a more recent compliance survey ( $\mathrm{R}$. Cromie in litt.) also support this conclusion. There was one prosecution and conviction under the Lead Shot Regulations between 1999-2020. Defra ministers and officials undertook to begin consideration of improved implementation and enforcement of the Lead Shot Regulations in 2016, but no new prosecutions have been initiated since then.

The extensive illegal shooting of ducks in England may relate to the Lead Shot Regulations being only partial, in that they cover only the shooting of certain species (largely ducks and geese) and/or in certain places (listed wetlands and the foreshore). In Denmark, where there has been a statutory ban on the trade, possession and use of lead shotgun ammunition for all hunting and clay target shooting since 1996, illegal use of lead gunshot is very low. A study in Denmark in the 2016-2017 shooting season found that $3.1 \%$ of mallards had lead shot embedded in their tissues. In the 20162017 and 2017-2018 seasons combined, 1.8\% of sampled common pheasants contained embedded lead shot (Kanstrup \& Balsby 2019). Hence, the recent $2-3 \%$ non-compliance with legislation in Denmark is much lower than the reported $68 \%$ to $77 \%$ non-compliance for the shooting of ducks in England (Cromie et al. 2015).

Bans on trade in lead ammunition (in addition to use) are potentially more likely to be complied with, and more cost-effective to enforce, as the onus is on a relatively small number of individuals whose businesses and livelihoods could be impacted by illegal activity. The willingness of individual shooters to kill birds illegally using lead gunshot in the UK was illustrated in the survey coordinated by BASC in 2009 as part of the Defra-funded study of compliance (Cromie et al. 2010). Results from this survey suggested that, while understanding of the 'spirit' of the Lead Shot Regulations was good, 45\% of those legally obliged to use non-lead gunshot indicated that they never or only sometimes complied with the Regulations.

Shooting and rural land management organisations, conservation organisations, game distribution organisations and dealers, food retailers and human and wildlife scientists are all calling for an end to, or a reduction in, the use of some or all types of lead ammunition for quarry shooting in the UK (Group of Scientists 2014, BASC 2020, GWCT 2020, RSPB 2020b, WWT 2020, Waitrose 2020, Knepp Wild Range Meat 2021, National Game Dealers Association 2021). Evidence suggests that a total ban on trade, possession and use of lead ammunition would not only benefit wildlife and human health and the environment, but also help put an end to hundreds of thousands of the wildlife crimes committed annually in England. 


\section{ACKNOWLEDGEMENTS}

We thank Nicholas Aebischer for constructive criticism of our initial attempt to calculate duck bag totals for England and his advice on how to improve that calculation. We are grateful to Guy Shorrock for providing information from the RSPB Species Protection database and to Ruth Cromie for valuable discussions and comments.

\section{REFERENCES}

Aebischer, N.J. (2019) Fifty-year trends in UK hunting bags of birds and mammals, and calibrated estimation of national bag size, using GWCT's National Gamebag Census. European Journal of Wildlife Research, 65, 64. https://doi.org/10.1007/s10344-019-1299-x

AEWA (1999) Resolution 1.14 Phasing out of lead shot in wetlands. First Meeting of the Parties to the Agreement on the Conservation of AfricanEurasian Migratory Waterbirds (AEWA), 6-9 November 1999, Cape Town, South Africa. http://www.unepaewa.org/sites/default/files/document/final_res1 4 0.doc.

AEWA $\bar{A}$ (2002) Resolution 2.2 Phasing out of lead shot for hunting in wetlands. Second Meeting of the Parties to the Agreement on the Conservation of African-Eurasian Migratory Waterbirds (AEWA), 25-27 September 2002, Bonn, Germany. $\quad$ http://www.unepaewa.org/en/document/phasingout-lead-shothunting-wetlands-2.

AEWA (2008) Resolution 4.1 Phasing out of lead shot for hunting in wetlands. Fourth Meeting of the Parties to the Agreement on the Conservation of African-Eurasian Migratory Waterbirds (AEWA), 15-19 September 2008, Antananarivo, Madagascar. http://www.unepaewa.org/sites/

default/files/document/res4_1_phasing_out lea d_shot_final_0.pdf.

BASC (2009) Non-lead Shot: Restrictions on Lead Shot in the UK. Information Sheet. BASC, Rossett , UK.

BASC (2013a) Why comply? Comply with the law on lead shot or face a ban. Shooting and Conservation July/August 2013: 16-17.

BASC (2013b) Fight the threat to lead shot now. Have you signed the pledge? Shooting and Conservation September/October 2013: 9.

BASC (2020) A joint statement on the future of shotgun ammunition for live quarry shooting. https://basc.org.uk/a-joint-statement-on-thefuture-of-shotgun-ammunition-for-live-quarryshooting

Brochet, A.L., Van Den Bossche, W., Jbour, S., Ndang'ang'a, P.K., Jones, V.R., Abdou, W.A.L.I., Al-Hmoud, A.R., Asswad, N.G., Atienza, J.C., Atrash, I., Barbara, N., Bensusan, K., Bino, T., Celada, C., Cherkaoui, S.I., Costa, J., Deceuninck, B., Etayeb, K.S., FeltrupAzafzaf, C., Figelj, J., Gustin, M., Kmecl, P.,
Kocevski, V., Korbeti, M., Kotrosan, D., Mula Laguna, J., Lattuada, M., Leitao, D., Lopes, P., López-Jiménez, N., Lucić, V., Micol, T., Moali, A., Perlman, Y., Piludu, N., Portolou, D., Putilin, K., Quaintenne, G., RamadanJaradi, G., Ruzic, M., Sandor, A., Sarajli, N., Saveljić, D., Sheldon, R.D., Shialis, T., Tsiopelas, N., Vargas, F., Thompson, C., Brunner, A., Grimmett, R. \& Butchart, S.H.M. (2016) Preliminary assessment of the scope and scale of illegal killing and taking of birds in the Mediterranean. Bird Conservation International, 26, 1-28. https://doi:10.1017/S0959270915000416

Brochet, A., Van Den Bossche, W., Jones, V.R., Arnardottir, H., Damoc, D., Demko, M., Driessens, G., Flensted, K., Gerber, M., Ghasabyan, M., Gradinarov, D., Hansen, J., Horváth, H., Karlonas, M., Krogulec, J., Kuzmenko, T., Lachman, L., Lehtiniemi, T., Lorgé, P., Lötberg, U., Lusby, J., Ottens, G., Paquet, J., Rukhaia, A., Schmidt, M., Shimmings, P., Stipnieks, A., Sultanov, E., Vermouzek, Z., Vintchevski, A., Volke, V., Willi, G. \& Butchart, S.H.M. (2019) Illegal killing and taking of birds in Europe outside the Mediterranean: assessing the scope and scale of a complex issue. Bird Conservation International, 29, 10-40. https://doi:10.1017/S0959270917000533

Clopper, C. \& Pearson, E.S. (1934). The use of confidence or fiducial limits illustrated in the case of the binomial. Biometrika, 26, 404-413.

Coffey, T. (2016) Letter from the Parliamentary Under Secretary for Environment and Rural Affairs to the Chair of the LAG. http://www.leadammunitiongroup.org.uk/wpcontent/uploads/2015/06/Letter-from-ThereseCoffey-Nov-16-rdct.pdf

Cromie R.L., Brown M.J. Hughes B., Hoccom D.G. \& Williams G (2002) Prevalence of shot-in pellets in mallard purchased from game dealers in England in winter 2001/2002. Compliance with the Lead Shot Regulations (England) during winter 2001/02. RSPB. Sandy, UK.

Cromie, R., Loram, A., Hurst, L., O’Brien, M., Newth, J., Brown, M. \& Harradine, J. (2010) Compliance with the environmental protection (Restrictions on Use of Lead Shot) (England) Regulations 1999. Defra, Bristol, UK.

Cromie, R., Newth, J., Reeves, J., O’Brien, M., Beckmann, K \& Brown, M. (2015) The sociological and political aspects of reducing lead poisoning from ammunition in the UK: why the transition to non-toxic ammunition is so difficult. Pages 104-124 in: R.J. Delahay \& C.J. Spray (eds.) Proceedings of the Oxford Lead Symposium. Lead Ammunition: understanding and minimising the risks to human and environmental health. Edward Grey Institute, University of Oxford, Oxford, UK.

Ellis, M. (2017) Leading questions. Shooting and Conservation July/August 2017: 39. 
Graffius, C. (2014) Lead shot. Obey the law or face a total ban. Shooting and Conservation September/October 2013: 35.

Green, R.E., Taggart, M.A., Pain, D.J., Clark, N.A., Clewley, L., Cromie, R., Elliot, B., Green, R.M.W., Huntley, B., Huntley, J., Leslie, R., Porter, R., Robinson, J.A., Smith, K.W., Smith, L., Spencer, J. \& Stroud, D. (2021) Effect of a joint policy statement by nine UK shooting and rural organisations on the use of lead shotgun ammunition for hunting common pheasants Phasianus colchicus in Britain. Conservation Evidence Journal, 18, 1-9. https://doi.org/10.52201/CEJ18ROTZ8607

Group of Scientists (2014) Wildlife and Human Health Risks from Lead-Based Ammunition in Europe. A Consensus Statement by Scientists. https://www.zoo.cam.ac.uk/system/files/docum ents/European-Statement.pdf

GWCT (2020) Waitrose- our stance on lead shot. https://www.gwct.org.uk/blogs/news/2020/octo ber/video-waitrose--our-stance-on-lead-shot/

Her Majesty's Stationary Office (1999) The Environmental Protection (Restriction on Use of Lead Shot) (England) Regulations 1999. UK Statutory Instrument No 2170. https://www.legislation.gov.uk/uksi/1999/2170/ made.

Her Majesty's Stationary Office (2002) The Environmental Protection (Restriction on Use of Lead Shot) (England) (Amendment) Regulations 2002. UK Statutory Instrument No 2102. https://www.legislation.gov.uk/uksi/2002/2102/ contents/made.

Her Majesty's Stationary Office (2003) The Environmental Protection (Restriction on Use of Lead Shot) (England) (Amendment) Regulations 2003. UK Statutory Instrument No 2512. https://www.legislation.gov.uk/uksi/2003/2512/ contents/made.

Kanstrup, N. \& Balsby, T.J.S. (2019) Danish pheasant and mallard hunters comply with the lead shot ban. Ambio, 48, 1009-1014. https://doi.org/10.1007/s13280-019-01152-7

Knepp Wild Range Meat (2021) https://www.kneppwildrangemeat.co.uk/sustain ability

Mateo, R., N. Vallverdu'-Coll, A. Lo'pez-Antia, M.A. Taggart, M., Martı'nez-Haro, R. Guitart, and M.E. Ortiz-Santaliestra. (2014) Reducing Pb Poisoning in Birds and $\mathrm{Pb}$ Exposure in Game Meat Consumers: The Dual Benefit of Effective $\mathrm{Pb}$ Shot Regulation. Environment International, 63, 163-168. http://dx.doi.org/10.1016/j.envint.2013.11.006

National Game Dealers Association (2021) https://www.nationalgamedealersassociation.co. $\mathrm{uk} /$ news
Newth, J.L., Cromie, R.L., Brown, M.J., Delahay, R.J., Meharg, A.A., Deacon, C., Norton, G.J., O'Brien, M.F., Pain, D.J. (2012) Poisoning from lead gunshot: still a threat to wild waterbirds in Britain. European Journal of Wildlife Research, 59, 195-204. https://DOI 10.1007/s10344-0120666-7

PACEC (2006) The economic and environmental impact of sporting shooting in the UK. Public and Corporate Economic Consultants, London.

PACEC (2014) The Value of Shooting. The economic, environmental, and social benefits of shooting sports in the UK. An independent survey report prepared by PACEC (Public and Corporate Economic Consultants) on behalf of UK shooting and countryside organisations. Public and Corporate Economic Consultants, London, UK.

RSPB (2011) First conviction for illegal use of lead shot. Legal Eagle, 65, 6.

RSPB (2020a) Bird Crime 2019. RSPB, Sandy, UK. RSPB (2020b) https://www.rspb.org.uk/ globalassets/downloads/documents/birds-andwildlife/gamebird-shooting-review/leadammunition.pdf

Stroud, D.A. (2003) The status and legislative protection of birds of prey in Europe. Pp. 51-84. In: Thompson, D.B.A., Redpath, S.M., Fielding, A.H., Marquiss, M. \& Galbraith, C.A. (eds.) Birds of prey in a changing environment. The Stationary Office, Edinburgh, UK.

Stroud, D.A. (2015) Regulation of some sources of lead poisoning: a brief review. Pages 8-26 in: R.J. Delahay \& C.J. Spray (eds.) Proceedings of the Oxford Lead Symposium. Lead Ammunition: understanding and minimising the risks to human and environmental health. Edward Grey Institute, University of Oxford, Oxford, UK.

Truss, E. (2016) Letter from Secretary of State to the Chair of the Lead Ammunition Group, 12 July 2016. http://www.leadammunitiongroup.org.uk/ wp-content/uploads/2016/07/Letter-from-

Elizabeth-Truss-to-John-Swift-13-July2016.pdf

Waitrose (2020) 'Lead Shot Pledge' on Waitrose online 'Animal Welfare page' https://www.waitrose.com/home/inspiration/abo ut_waitrose/the_waitrose_way/waitrose_animal welfarecommitments.html

Widemo, F. (2021) Shooting habits and habitatseffects of education and legislation on the phasing out of lead shot. Environmental Science and Policy, 118, 56-62. https://doi.org/10.1016/j.envsci.2021.01.010

WWT (2021) https://www.wwt.org.uk/ourwork/projects/tackling-lead-ammunitionpoisoning

The Conservation Evidence Journal is an open access online journal devoted to publishing the evidence on the effectiveness of management interventions. The other papers from the Conservation Evidence Journal are available from www.conservationevidencejournal.com. The pdf is free to circulate or add to other websites and is licensed under the Creative Commons Attribution 4.0 International License http://creativecommons.org/licenses/by/4.0/. Under this licence, authors retain ownership of the copyright for their articles. 